\title{
New Design of a Multiband Microstrip Antenna
}

\author{
S. El Kilani ${ }^{1}$ Larbi El Abdellaoui ${ }^{1}$, A.Tajmouati, A.Errkik ${ }^{1}$,Mohamed Latrach ${ }^{2}$
}

${ }^{1}$ LMEET FST of Settat, Hassan 1st University, Morocco

${ }^{2}$ Microwave group, ESEO ANGERS France

Dr.samir.2014@gmail.com

\begin{abstract}
This paper proposes a multiband microstrip patch antenna covers a multiple operating frequency bands PCS/DCS/LTE/WIFI. The overall dimension of the proposed antenna is $65 \times 67.05 \mathrm{~mm}^{2}$ printed on an FR4 substrate, having $1.6 \mathrm{~mm}$ as thickness with a relative dielectric permittivity of 4.4 and 0.025 for loss tangent. The proposed antenna was study and validated by using electromagnetic software's CST-MW. Three bands (1.811-1.828 GHz, 2.631-2.749 GHz and 4.554-5.457 GHz) are achieved by inserting a slot on the top patch and ground. The radiation pattern has acceptable response with low cross polarization at both E-plane and H-plane.
\end{abstract}

Keywords: Microstrip patch antenna, Multiband planar antennas, DCS, PCS, WIFI.

\section{Introduction}

Nowadays the multiband antenna become more and more requested, all mobiles equipments required covering all communication service includes $2 \mathrm{G} / \mathrm{GSM} 900 / \mathrm{PCS}$, 3G/UMTS/HSDPA/WiFi/ Bluetooth and 4G/LTE, In various mobile communication services, long-term evolution (LTE) is one of the widely used communication systems as a fourth-generation wireless service. Because each nation or wireless carrier uses different frequency bands, a multiband antenna is desirable [1]. Since each communication protocol may operate in distinctive frequency bands, instead of using several antennas, it is highly useful to have one multiband antenna to meet the need of multiple communication systems [2].

Microstrip patch antenna is promising to be a good candidate for the future technology. Microstrip patch antenna consists of a dielectric substrate, with a ground plane on the other side. Due to its advantages such as low weight, low profile planar configuration, low fabrication costs and capability to integrate with microwave integrated circuits technology, the microstrip patch antenna is very well suited for applications such as wireless communications system, cellular phones, pagers, Radar systems and satellite communications systems [3, 4].

To achieve the multiband characteristics many efforts has been made by the researchers in recent years [5]-[6]. The methods such as notch technique [7], slots technique [8] and fractal method [9] are used to design multiband antennas. By introducing these different types of methods and techniques in the geometry of microstrip patch antenna and proper selection of feeding technique helps to achieve the multiband characteristics easily [10].

In this paper, a compact multiband design of Microstrip patch antenna is proposed. The bandwidth has improved by adding slots and by fine tuning to some parameters to reach the best possible result. The multiband antenna covers following frequency bands: DCS/PCS (1.811-1.828 MHz), LTE2500 (2.631-2.749 
$\mathrm{GHz})$, WIFI/Bluetooth (4.554-5.457 GHz) [11-12]. This design is fully planar, fairly compact, and low cost by using a low cost FR4 substrate material.

\section{Antenna Design}

Figure 1 shows the stricture of the proposed multi-band antenna for PCS/DCS/LTE/WIFI, where we can see the top and the bottom faces of the final circuit. The antenna is a planar microstrip patch antenna designed on an FR4 substrate having $1.6 \mathrm{~mm}$ as thickness with a relative dielectric permittivity of 4.4 and 0.025 for loss tangent. With dimensions of $65 \times 67.05 \times 1.6 \mathrm{~mm}^{3}$ in FR4 substrate and $34.11 \times 30.4$ of antenna radiating part, a $50 \Omega$ microstrip line is used to feed the antenna for better impedance matching. The ground plane of the proposed antenna is modified and optimized to reach the multiband behavior in the suitable frequency bands.

With the help of the fundamental equations given in this paper [11] we find the first dimensions values of the patch antenna.

The width of the microstrip patch is finding by:

$$
W=\frac{c}{2 f r} \sqrt{\frac{2}{\varepsilon_{r}+1}}
$$

Effective dielectric constant is given by:

$$
\varepsilon_{\text {reff }}=\frac{\varepsilon_{r}+1}{2}+\frac{\varepsilon_{r}-1}{2}\left[1+12 \frac{h}{w}\right]^{-\frac{1}{2}}
$$

The extension length $(\Delta \mathrm{L})$ is calculated by:

$$
\Delta L=0.412 h \frac{\left(\varepsilon_{r}+0.3\right)\left(\frac{w}{h}+0.264\right)}{\left(\varepsilon_{r}-0.258\right)\left(\frac{w}{h}+0.8\right)}
$$

Length $L$ of the patch:

$$
L=\frac{c}{2 f_{r} \sqrt{\varepsilon_{\text {reff }}}}-2 \Delta L
$$

The length and width of the ground plane is estimated by this equation:

$$
\begin{gathered}
w_{g}=6 h+w \\
L_{g}=6 h+L
\end{gathered}
$$


After many series of optimization by using CST, we have obtained the different optimized parameters listed in Table1.

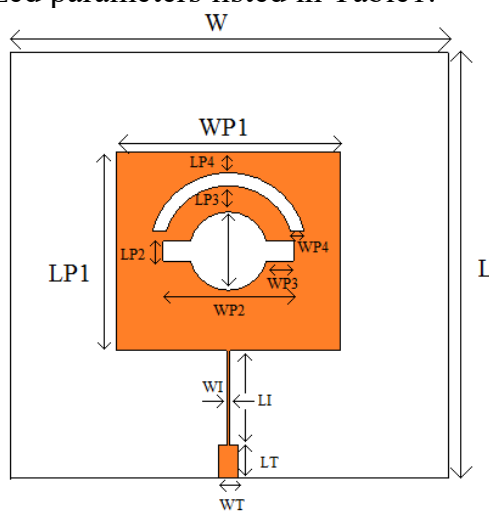

(a) Top view

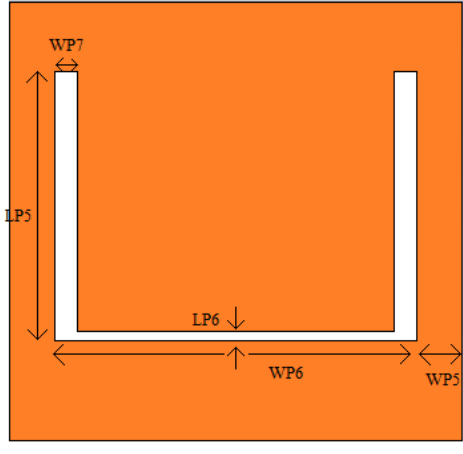

(b) Bottom view

Fig.1. Geometry of the proposed Antenna

Table1. Parameters of the proposed antenna (unit in $\mathrm{mm}$ )

\begin{tabular}{|c|c|c|c|}
\hline Parameter & Value & Parameter & Value \\
\hline L & 65 & WP3 & 4.19 \\
\hline W & 67.05 & LP3 & 4 \\
\hline WP1 & 34.11 & WP4 & 2.079 \\
\hline LP1 & 30.04 & LP4 & 3.5 \\
\hline WT & 3 & WP5 & 7.725 \\
\hline LT & 5 & LP5 & 40 \\
\hline WI & 0.5 & WP6 & 53.6 \\
\hline LI & 14.5 & LP6 & 1.5 \\
\hline WP2 & 20 & WP7 & 3.3 \\
\hline LP2 & 3 & WS & 11.75 \\
\hline
\end{tabular}

\section{Results and Discussion}

The proposed antenna is simulated by using cst microwave, whose numerical analysis is based on the Finite Element method [12]. Figure.2 shows the return loss simulation results of the proposed antenna. The simulation results ensure that the antenna covers multi-band frequencies for wireless applications. For a return loss less than $10 \mathrm{~dB}$, we can deduce that the antenna operates in three frequency bands (1.811-1.828 MHz), (2.631-2.749 GHz) and (4.554-5.457 GHz), which covers DCS/ PCS/ WIFI/ Bluetooth/ WIMAX. The third band frequency is controlled by adjusting the total dimensions of the planar antenna but the first and second one are controlled by the geometry and dimensions of the ground plane. 


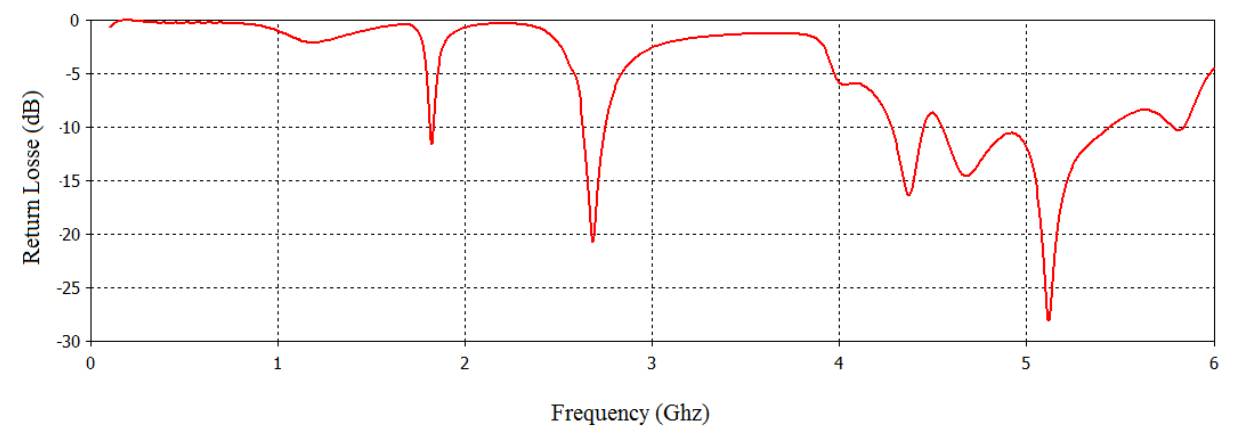

Fig.2. return losses obtained by CST-MW.

As depicted in Figure 2, The simulation results show that this antenna can be suitable for three frequency bands (1.811-1.828 GHz, 2.631-2.749 GHz and 4.554-5.457 $\mathrm{GHz}$ ), which covers DCS/PCS/LTE/WIFI/Bluetooth for mobile phone applications.

Figure 3 shows the simulated three-dimensional (3D) radiation patterns of the proposed antenna at three resonant frequencies $1.87 \mathrm{GHz}, 2.637 \mathrm{GHz}$ and $5.126 \mathrm{GHz}$. We can conclude that the proposed antenna can radiate unidirectional pattern at all the operating frequency bands. The simulated surface current of the proposed antenna, is presented in Figure 4.

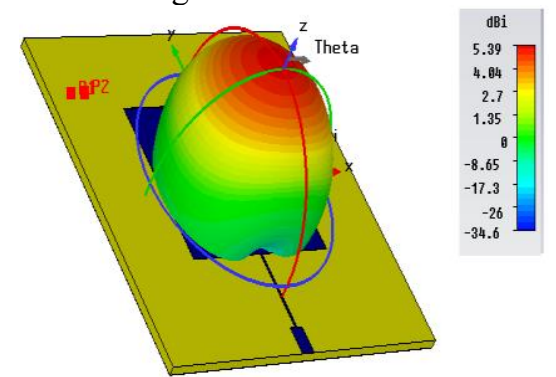

$\mathrm{F}=1.87 \mathrm{Ghz}$

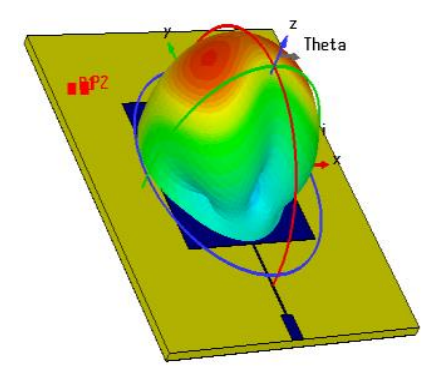

$\mathrm{F}=2.637 \mathrm{Ghz}$
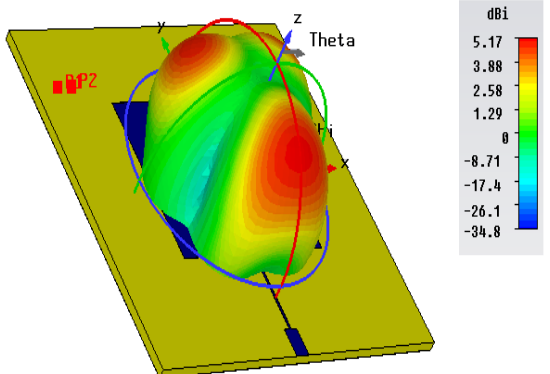

$$
\mathrm{F}=5.126 \mathrm{Ghz}
$$

Fig.3. The simulated radiation patterns of the proposed antenna at different resonant frequencies. 


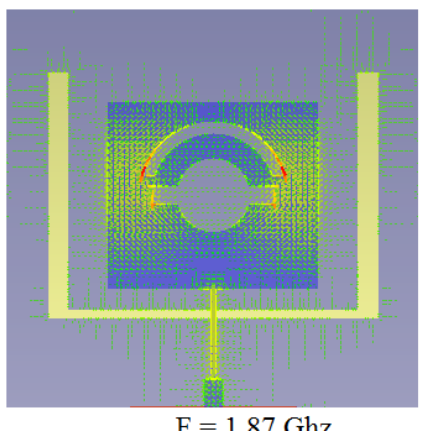

$\mathrm{F}=1.87 \mathrm{Ghz}$

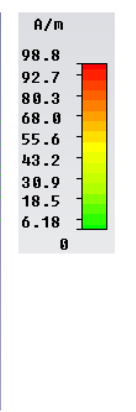

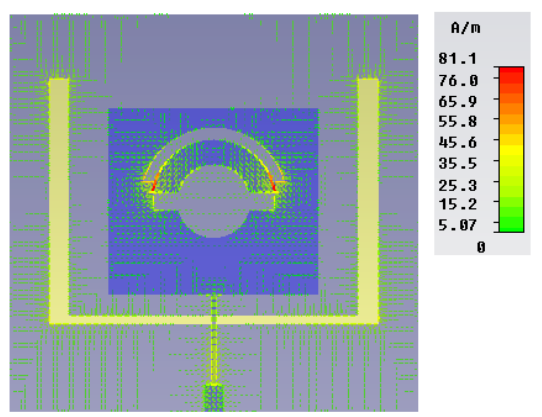

$\mathrm{F}=2.637 \mathrm{Ghz}$

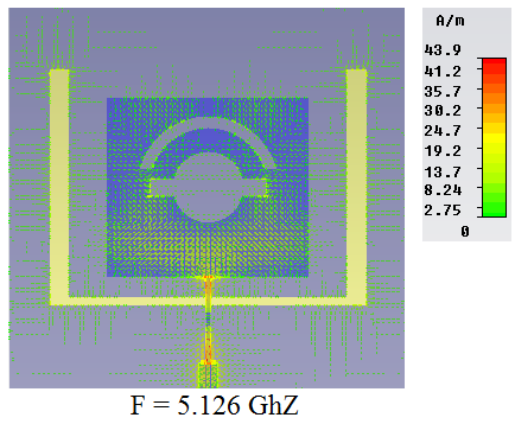

Fig.5. Simulated surface current of the proposed antenna at different resonant frequencies.

\section{Conclusion}

In this work, A multi-band compact patch with microstrip is presented for 1.87, 2.637, $5.126 \mathrm{GHz}$ application and validated into simulation by using an electromagnetic solvers. Multiband was achieved by adding the slot in the patch and the ground. The antenna characteristic and radiation pattern is satisfactory for most of the wireless system because is unidirectional and can protect humane head. The different steps followed in this study can be used to validate an antenna for others frequency bands.

\section{References}

[1] A. Ghosh, R. Ratasuk, B. Mondal, N. Mangalvedhe, and Thomas, "LTE-advanced: nextgeneration wireless broadband technology," IEEE Wireless Communications, vol.17, no.3, pp.10-22, 2010.

[2] W.-J. Liao, S.-H. Chang, and L.-K. Li, A compact planar multiband antenna for integrated mobile devices, Progress In Electromagnetics Research 109 (2010) 1-16.

[3] FUJIMOTO T. Wideband stacked square microstrip antenna with shorting plates. IEICE Trans B: Communications. 2008 May 1;E91-B(5):1669-72.

[4] Lin S-, Row J-. Bandwidth enhancement for dual-frequency microstrip antenna with conical radiation. Electronics Letters. 2008;44(1):2-3.

[5] Jyoti Kapil, Hardyal Singh, "Compact multiband microstrip antenna for wireless communication systems," International Journal of Electrical, Electronics and Data Communication, Vol. 4, Issue 3, Mar. 2016.

[6] Hau Ran Cheong, Kim Ho Yeap, Koon Chun Lai, "A compact CPW-fed antenna with fractal s-shaped patches for multiband applications," Microwaves and Optical Technology Letter.,Vol. 59, Issue3, Mar. 2017. 
[7] Mustapha El Halaoui, Abdelmoumen Kaabal, Hassan Asselman, Saida Ahyoud, and Adel Asselman,"Multiband Planar Inverted-F Antenna with Independent Operating Bands Control for Mobile Handset Applications," Inernational journal of Antennas and Propagation, Article ID 8794039, 13 pages, 2017.

[8] Manjiri Gogate, Aditya Desai, Madhuri Bhujbal, "Multiband Patch Antenna for Wireless Devices," International Conference on Emanations in Modern Technology and Engineering, Vol. 5, Issue 3, Mar 2017.

[9] Ajay Singh, G.P. Singh, Manvendra, Prinu C. Philip, Mukesh Kumar, Rohini saxena, "Analysis of V Slot Multiband Microstrip patch Antenna for S, C and X Bands," International Journal of Engineering Trends and Technology (IJETT), Vol. 48, June. 2017.

[10] Hatem Rmili,Donia Oueslati, Imen Ben, Trad Jean, Marie Floch, Abdullah Dobaie, and Raj Mittra, "Investigation of a Random-Fractal Antenna Based on a Natural Tree-Leaf Geometry," Hindawi International Journal of Antennas and Propagation, November. 2017.

[11] Balanis, C. A. Antenna Theory: Analysis and Design, 3rd ED.John Wiley \& Sons, Inc., 2012.

[12] Guy A. E. Vandenbosch and Alexander Vasylchenko, A practical guide to 3D electromagnetic software tools, Microstrip Antennas, Prof. Nasimuddin Nasimuddin (Ed.), ISBN: 978-953-307-247-0, InTech (2011). 